\title{
Sciendo
}

DOI: $10.2478 /$ jolace-2019-0002

\section{EFL Teachers' Moral Dilemma and Epistemic Beliefs}

\author{
Amin Karimnia \& Meisam Jamadi \\ Islamic Azad University, Iran \\ aminkarimnia@yahoo.com
}

\begin{abstract}
This study investigated the relationship between English teachers' epistemological beliefs and moral dilemma. In doing so, 70 English teachers were selected from different language institutes and were included in the research sample. The instruments used to collect the data included the Schommer Epistemological Questionnaire (SEQ) and the Defining Issues Test (DIT). The collected data were analyzed using Pearson Product Moment Correlation method and descriptive statistics in SPSS software. The findings revealed that the participants believed that knowledge improves with experience over time, and that there was also an innate ability to acquire knowledge. They also displayed conflicting views about the simplicity/complexity of knowledge. The analysis of different stages of moral development in the views of the English teachers showed an ascending trend in the moral development from stage 2 (the focus on personal interests) through stage 6 (appeal to intuitive moral principles/ideals). Besides, significant differences were found among different stages of moral development as assessed by the EFL teachers and also in terms of the impact of different moral reasoning schemas on the participants when making judgments about different moral dilemmas.
\end{abstract}

Key words: epistemology, epistemic beliefs, moral reasoning/dilemma, foreign language teaching

\section{Introduction}

A number of studies have established a connection between teachers' beliefs about knowledge and their teaching practices (Chen, Morris, \& Mansour, 2015; Çetin-Dindar, Kirbulut, \& Boz, 2014; Mansour, 2013; Chai et al., 2006; Deniz, 2011). The analysis of epistemic beliefs within teacher education programs and their development is highly important, as these beliefs affect students' and instructors' academic performance (Balakrishnan \& Narvaez, 2016; Sanger, 2008). Research shows that people's epistemic beliefs affect their motivational beliefs including the way they employ learning strategies, regulate their academic performance, and show consistent behaviors in self-regulatory and achievementoriented procedures (Schommer et al., 2000; Topcu, 2011; Ozgelen, 2012).

An equally important variable that may be influenced by epistemological beliefs is moral reasoning. Moral reasoning is a capacity that enables us to think 
consciously and deliberately about morality; it involves thinking with moral considerations that often lead to a moral conclusion (Saunders, 2015). Moral conflicts are also defined as including those situations in which a person's moral perspective may be sensibly interpreted as directing the person to perform two incompatible actions (Dwyer, 2009; Haidt \& Bjorklund, 2008a; Horgan \& Timmons, 2007).

To clarify the moral challenges, a teacher may face two situations: first, there are cases where a teacher has difficulty in deciding how to deal with the students. The conflict includes teacher's decisions about punishing a particular student. In this situation, a student is disturbing the class and the teacher makes a quick decision to ask the student to leave the class to maintain the peaceful environment for the rest of the students. The teacher is concerned about the appropriate way of doing this and his/her way of dealing with this particular student. Another situation is what has happened to one of the authors of the present study. He remembers a situation from some years ago in which he had problems in deciding between two grades for an academically weak student. He decided to give the student a failing grade, and he is still concerned about the effects of his decision on that student.

There is no single right or wrong way to handle situations such as the ones described above; we only wish to argue that they can be best conceptualized in terms of the tensions of morality and power that are unavoidably inherent in the exercise of authority. These tensions can never be resolved; they present constant difficult choices to the teachers, and each time they arise they should be dealt with in a new or different way in complex and ambiguous moral contexts in which decisions are rarely easy or straightforward (Hart, Matsuba \& Atkins, 2014; Gibbs, 2013; Paxton, Ungar \& Greene, 2011).

The purpose of this study is (a) to investigate types of epistemological beliefs (omniscient authority, simple knowledge, etc.) in a sample of EFL teachers; (b) and to find the relationship between their epistemological beliefs with their moral reasoning.

\section{Literature review}

\subsection{Epistemological beliefs}

Epistemological beliefs are those beliefs that are concerned about "the nature of knowledge and learning" (Schommer, 1980, p. 78). Studies concerned with teachers' epistemological beliefs (Chan, 2004; Chan \& Elliott, 2004; Cheng, Chan, Tang, \& Cheng, 2009; Deniz, 2011; Kang, 2008; Ozgelen, 2012) often make use of Schommer's model. In the 1980s, Schommer integrated epistemological dimensions and developed a system of independent beliefs, in which a number of beliefs were supposed to frame the individuals' personal epistemology. It is also considered that one's epistemological beliefs can evolve and refine over time. 
This accounts for why there are contradictory beliefs among people concerning the nature of knowledge. For instance, some individuals may consider knowledge to include isolated pieces of information, while others may hold the belief that the deep learning of knowledge is a gradual process. Many scholars (Gill, Ashton \& Algina, 2004; Horgan \& Timmons, 2007)) have addressed how epistemological beliefs are correlated with psychological processes, such as mathematics instruction and learning.

Epistemological beliefs and the learning approach have also been studied in terms of five epistemic dimensions as measured through the Epistemological Beliefs Inventory (EBI) (Bendixen et al., 1998). These dimensions include (a) simple knowledge (knowledge consists of concrete facts); (b) certain knowledge (absolute knowledge exists and must be discovered); (c) omniscient authority (authorities have access to otherwise inaccessible knowledge); (d) quick learning (learning occurs in a quick or not-at-all fashion); and (e) fixed ability (the ability to acquire knowledge is innate or genetically determined).

\subsection{Moral reasoning}

Recent decades have witnessed a growing interest in the moral domain of teaching among educational researchers and teacher educators (Balakrishnan \& Narvaez, 2016). The moral dimension of teaching might become more concrete when a teacher faces a conflict in his professional conduct. Many educational conflicts require decision making from a teacher.

Different scholars assume that teaching is essentially and fundamentally a moral enterprise (Campbell, 2014; Campbell, 2008; Sanger, 2008). How a teacher cares for students is thought to be among the most important of all professional matters. Moreover, morality is at the heart of the teacher's disciplinary knowledge, that knowing a discipline is not merely a matter of cognitive attainment but an ethical achievement, a matter of having embraced a set of values characteristic of preferred modes of inquiry. To teach is to be embedded in a world of uncertainty and of hard choices, what a teacher does and how he or she thinks is morally laden (Levin, 2015; Hansen, 2001).

Conflicts among values, norms, and beliefs, pervade teaching; some originating in the way in which teaching is structured and in how authority is understood and enacted and in the sometimes competing interests of teachers, students, and their parents (Noddings, 2002). Teachers understand and respond to these conflicts differently. Based upon a wide range of life experience, patterns are apparent in how teachers respond to moral dilemmas, indicating differences in levels of moral and ethical sensitivity and understanding (Rabin \& Smith, 2013; Carr, 2000). 


\section{Research questions}

As was mentioned earlier, the present study aimed to explore Iranian English teachers' epistemological beliefs and moral reasoning and to find any relationship between these two variables. To achieve this purpose, two main questions guided the study:

What types of epistemological beliefs (omniscient authority, simple knowledge, certain knowledge, innate ability, or quick learning) do English teachers exhibit?

What is the relationship between English teachers' epistemological beliefs and their moral reasoning?

\section{Method}

The main objective of this study was to address Iranian English teachers' epistemological beliefs and moral reasoning. To this end, a survey methodology was used to determine the types of epistemological beliefs held by Iranian EFL teachers and the correlation between their epistemological beliefs and moral reasoning. This section describes the procedures taken to conduct this study.

\subsection{Participants}

Based on the convenient sampling procedure, 70 Iranian English teachers were selected as participants from different language institutes in three cities in Iran (Bandar-Abbas, Shiraz and Fasa). All participants were native Iranian English teachers at elementary, intermediate and advanced levels at the time this study was conducted. The participants were aged 26.5 years on average, while the youngest one was 25 and the oldest 34, and all of them had at least three years of teaching experience. The most experienced one had 8 years of experience.

\subsection{Instruments}

Two instruments were used to collect the quantitative data: the Schommer Epistemological Questionnaire (SEQ) and the Defining Issues Test (DIT), which was developed based on the Kohlberg's moral reasoning theory and included six stages of moral development. To collect the qualitative data, the studies conducted by Schommer (1990) and Cheng et al. (2009) were used to design an epistemological beliefs interview protocol. Then semi-structured interviews were conducted. Eight English teachers were conveniently selected for the interview. Each interview was audio-recorded and transcribed word for word for further analysis. 


\subsection{Data collection and analysis}

Initially, Schommer Epistemological Questionnaire (SEQ, 1989) was distributed among the participants to evaluate their epistemological beliefs. To this end, the participants were asked to evaluate 63 statements about the nature of learning and knowledge using a five-point scale from 1 (strongly disagree) to 5 (strongly agree). Depending on the score an individual received in the survey, his/her simplicity or sophistication of beliefs was decided. The SEQ consisted of 5 dimensions, including omniscient authority, simple knowledge, certain knowledge, innate ability, and quick learning. The second instrument, the Defining Issues Test (DIT) that was developed based upon the Kohlberg's (1971) moral reasoning theory, includes six stages of moral development. The participants were asked to read a story including a moral dilemma and then were required to make a judgment about this dilemma. Each case included one dilemma that was followed by 12 statements.

The statements were assessed based on a five-point Likert scale. The 12 statements for each story represented different stages of moral development. Some solutions regarding these dilemmas were assumed to represent different levels of moral reasoning. Percentage scores were derived from participants' responses to the 12 statements by calculating the ratio of their selection of statements. Upon the administration of the questionnaires, the participants' responses were scored and codified for data analysis. In order to find out if a relationship existed between the two research variables, Pearson Product Moment Correlation method was run. To analyze the quantitative data, descriptive statistics including mean and standard deviations were calculated using SPSS software.

\section{Results}

\subsection{Types of epistemological beliefs exhibited by EFL teachers}

The first objective of the present study was to identify types of epistemological beliefs (omniscient authority, simple knowledge, certain knowledge, innate ability, or quick learning) exhibited by the Iranian English teachers under study. Nine items in the Schommer Epistemological Questionnaire (8, 47, 55, 57, 4, 15, 25, 28, and 62) measured the Iranian English teachers' views about the ability to learn. Lower values on this scale would indicate that the individual believed in the fixity of knowledge at birth, while higher values would show the individual's idea that knowledge improved with experience and over time. Table 1 presents the descriptive statistics concerning the participants' views about the ability to learn: 
Table 1: Descriptive Statistics for the Participants' Views About the Ability to Learn

\section{Distribution}

Scale 1 Min Max Mean Below the Mean Above the

mean mean

\begin{tabular}{lllllll}
\hline Innate ability & 22.00 & 36.00 & 29.1857 & $45.7 \%$ & $14.3 \%$ & $40 \%$
\end{tabular}

As it is shown in Table 1, participants' scores on the first scale in the questionnaire (innate ability) ranged from 22 to 36 (out of 45). Their mean score was 29.18. This showed that the participants generally believed that knowledge would improve with experience and over time. The distribution of the participants' scores also indicated that $45.7 \%$ of the participants scored more than one standard deviation below the mean, while $40 \%$ of them scored more than one standard deviation above the mean. The values implied that $45.7 \%$ of the participants believed in the innate ability to acquire knowledge, while $40 \%$ of them contended that knowledge improved over time as an individual gained more experienced. However, the remaining 14.3\% who scored one standard deviation either below or above the mean expressed neural views in this regard. The second scale in the questionnaire (including items 11, 16, 17, 19, 22, 23, 33, 56,58 , and 59) measured the participants' attitudes with regard to the structure of knowledge (simple knowledge), as shown in Table 2:

Table 2: Descriptive Statistics for the Participants' Views about the Structure of Knowledge

Distribution

Scale 2 Min Max Mean Below the Mean Above the

I mean mean

\begin{tabular}{llllllll}
\hline Structure of 24.00 & 37.00 & 29.2000 & & & \\
$44.3 \%$ & & & \\
& & & & & &
\end{tabular}

knowledge

The participants' scores on the second scale demonstrated a very close pattern to their scores on the first scale. As it can be seen, the scores of the participants on the second scale in the questionnaire (simple knowledge) varied from 24 to 37 (out of 50), with a mean score of 29.2. Participants with lower 
values on this scale maintained that knowledge was simple and based on isolated facts. In contrast, those with higher values held the belief that knowledge was more complex and composed of highly interrelated facts. Accordingly, it can be suggested that the participants on the average believed that knowledge had a complex nature and was made of highly interrelated facts. Furthermore, the distribution of the participants' scores showed that $44.3 \%$ of the participants held the belief that knowledge was simple and based on isolated facts. Yet, $42.80 \%$ of them considered knowledge to be a complex entity with many interrelated facts. Nevertheless, $12.9 \%$ of the participants were undecided with regard to the two extremes. Table 3 illustrates the participants' attitudes towards the speed of learning (quick learning) as measured through items 1, 10, 30, 39, $50,60,20,24$, and 52 in the questionnaire:

Table 3: Descriptive Statistics for the Participants' Views About the Speed of Learning

\begin{tabular}{|c|c|c|c|c|c|c|}
\hline \multirow[b]{2}{*}{ Scale 3} & \multirow[b]{2}{*}{ Min } & \multirow[b]{2}{*}{ Max } & \multirow[b]{2}{*}{ Mean } & \multicolumn{3}{|l|}{ Distribution } \\
\hline & & & & $\begin{array}{l}\text { Below the } \\
\text { mean }\end{array}$ & Mean & $\begin{array}{l}\text { Above the } \\
\text { mean }\end{array}$ \\
\hline $\begin{array}{l}\text { Speed } \\
\text { learning }\end{array}$ & of 21.00 & 45.00 & 28.9571 & $38.6 \%$ & $24.3 \%$ & $37.1 \%$ \\
\hline
\end{tabular}

As Table 3 shows, the participants' scores on the third scale in the questionnaire (speed of learning) ranged from 21 to 45 (out of 45), with a mean score of 28.95. Lower values on this scale would unveil the belief that learning was quick, and higher values were associated with the belief that learning was gradual and could be improved over time. As was the case with the two other scales discussed above, the participants generally maintained that learning could both a matter of quick processing and a gradual processing (improvable over time). The distribution of the participants' scores across this scale showed that $38.6 \%$ of the participants supported the view that learning was a quick process that would occur immediately, whereas $37.1 \%$ of them considered knowledge learning as a gradual process that would improve over time. In addition, $24.3 \%$ of the participants did not express a clear-cut decision about the speed of learning. Table 4 reports the participants' attitudes towards the stability of knowledge (certain knowledge), which was assessed through items 2, 12, 21, 34, 48, and 61 in the questionnaire:

Table 4: Descriptive Statistics for the Participants' Views about the Stability of Knowledge 


\begin{tabular}{|c|c|c|c|c|c|c|}
\hline \multirow[b]{2}{*}{ Scale 4} & \multirow[b]{2}{*}{ Min } & \multirow[b]{2}{*}{ Max } & \multirow[b]{2}{*}{ Mean } & \multicolumn{3}{|l|}{ Distribution } \\
\hline & & & & $\begin{array}{l}\text { Below the } \\
\text { mean }\end{array}$ & Mean & $\begin{array}{l}\text { Above the } \\
\text { mean }\end{array}$ \\
\hline $\begin{array}{l}\text { Stability of } \\
\text { knowledge }\end{array}$ & 15.00 & 32.00 & 19.2857 & $57.1 \%$ & $11.4 \%$ & $31.5 \%$ \\
\hline
\end{tabular}

As shown in Table 4, the participants' scores on the fourth scale in the questionnaire concerning the stability of knowledge varied from 15 to 32 (out of 32), with a mean score of 19.28. Participants with lower values on this scale advocated that knowledge involved absolute facts and that it was unchanging. In contrast, higher values showed the belief that knowledge is not absolute and certain. These figures generally indicated that the participants in this study favored generally the view that knowledge was composed of absolute facts rather than a tentative entity.

This is shown by the way the participants' scores were distributed across the knowledge stability continuum. As it can be seen, $57.1 \%$ of the participants supported the view that knowledge consisted of absolute facts, whereas only $31.5 \%$ of them considered knowledge to be a tentative entity. Furthermore, $11.4 \%$ of the participants supported neither of the extremes, adopting a neutral position concerning the stability of knowledge. The participants' attitudes towards the source of knowledge (omniscient authority) were assessed through items 13, 27, 3, 5, 7, 36, 40, and 46 in the questionnaire (see Table 5):

Table 5: Descriptive Statistics for the Participants' Views about the Source of Knowledge

\section{Distribution}

Scale 5 Min Max Mean Below the

mean

Mean

Above the

mean

Source of

knowledge

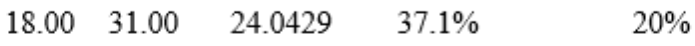

$48.3 \%$

Participants' scores on the fifth scale concerning the source of knowledge ranged from 18 to 31 (out of 40), and their mean score was 24.04. Lower values 
on this scale were in favor of the belief that knowledge was handed down by authority (37.1\%), while higher values emphasized that knowledge was acquired through reason or logic (48.3\%). Moreover, $20 \%$ of the participants were neutral in their views about the source of knowledge. Accordingly, it can be said that almost half of the participants in this study supported the view that knowledge could be acquired through reason or logic, as opposed to authority.

In order to see if there were any significant differences among the Iranian EFL teachers in terms of their types of epistemological beliefs, one-way ANOVA was conducted (see Table 6):

Table 6: Results of ANOVA test for differences in the participants' epistemological beliefs

$$
\text { Sum of Squares df Mean F }
$$

Square

\begin{tabular}{llllll}
\hline Between & 5456.874 & 4 & 1364.219 & 171.035 & .000
\end{tabular}

Groups

\begin{tabular}{llll}
\hline Within Groups & 2751.814 & 345 & 7.976 \\
\hline Total & 8208.689 & 349 &
\end{tabular}

As the results of one-way ANOVA suggested, there were significant differences among the participants concerning their different types of epistemological beliefs $(\mathrm{P}<0.01)$.

\subsection{The Relationship between English Teachers' Epistemological Beliefs and Their Moral Reasoning}

The second objective of the present study was to explore the relationship between Iranian English teachers' epistemological beliefs and their moral reasoning. To this end, the participants' responses to the items in the DIT were analyzed. The test shows different stages of moral development: (a) stage 2 was focused on the personal interests of the actor making the moral decisions; (b) stage 3 represented the focus on maintaining friendships, good relationships, and approval; (c) stage 4 addressed the tendency to maintain the existing legal system, rules, and formal organizational structure; (d) stage 5 measured the appeal to majority while maintaining minority rights; (e) and stage 6 presented the focus on appeal to intuitive moral principles/ideals. Table 7 shows the descriptive statistics for different stages of moral development among the participants in this study: 
Table 7: Descriptive Statistics for Different Stages of Moral Development

\begin{tabular}{lcccl}
\hline Stage & Min & Max & Mean & $\begin{array}{l}\text { Std. } \\
\text { Deviation }\end{array}$ \\
& & & & \\
\hline Stage 2 & 15.00 & 23.00 & 18.9000 & 2.23380 \\
\hline Stage 3 & 21.00 & 55.00 & 26.7143 & 4.09716 \\
\hline Stage 4 & 25.00 & 33.00 & 29.3286 & 1.90895 \\
\hline Stage 5 & 24.00 & 32.00 & 27.7000 & 2.14239 \\
\hline Stage 6 & 30.00 & 45.00 & 37.8000 & 3.41183 \\
\hline
\end{tabular}

As the mean scores suggested, there was an ascending trend in the moral development of the participants through the movement from stage 2 to stage 6 . This ascending trend was interrupted in stage 5 but it kept on moving to stage 6 . This showed that the participants in this study were less concerned about their personal interests (18.90) when making moral judgments (as represented in stage 2). In their moral judgments, they were more or less influenced by maintaining relationships (26.71), maintaining the existing legal system, rules, and formal organizational structure (29.32), and the focus on appeal to majority while maintaining minority rights $(27.70)$. However, they were mainly concerned about appeal to intuitive moral principles/ideals as was shown in stage 6 of moral development (with a mean score of 37.80). In order to find any significant differences among these different stages of the participants' moral development, one-way ANOVA was conducted (see Table 8).

As it is evident, there were significant differences among different stages of moral development $(\mathrm{p}<0.01)$. In order to discover any relationship between Iranian English teachers' epistemological beliefs and their moral reasoning, Pearson correlation test was run, as shown in Table 9.

The participants' personal interest schema was negatively correlated with most scales of epistemological beliefs except for scale 4 (stability of knowledge). However, the values of these correlations suggested that there were weak correlations between the personal interest schema and different scales of epistemological beliefs ( $\mathrm{P}>0.05)$, except for scale 5 (source of knowledge), which showed a significant negative correlation with the personal interest scale $(\mathrm{P}<0.05)$.

Table 8: Results of ANOVA for Differences in Moral Development Stages 


\begin{tabular}{lllllll}
\hline & Sum of Squares & df & $\begin{array}{l}\text { Mean } \\
\text { Square }\end{array}$ & F & Sig. \\
& & & & & \\
\hline Between & 12762.326 & 4 & 3190.581 & 383.013 & .000 \\
Groups & & & & & \\
\hline Within Groups & 2873.929 & 345 & 8.330 & & \\
\hline Total & 15636.254 & 349 & & & \\
\hline
\end{tabular}

Table 9: Correlations between Epistemological Beliefs and Moral Reasoning

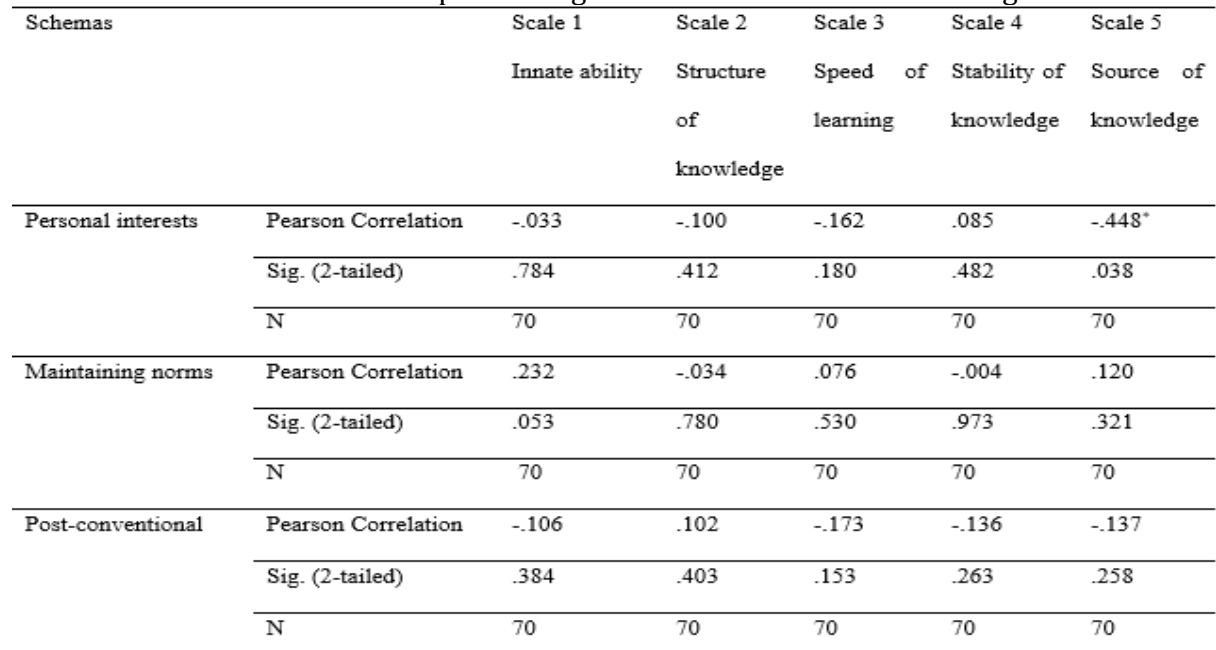

\section{Discussion}

The categories of epistemological beliefs displayed by the EFL teachers in the present study (omniscient authority, simple knowledge, certain knowledge, innate ability, or quick learning) were similar to those recognized in previous studies (e.g. Topcu, 2011; Baxter Magolda, 1993). Concerning the structure of knowledge, the English teachers again showed conflicting views, as some of them held the belief that knowledge was simple and based on isolated facts, while some considered knowledge to be a complex entity with many interrelated facts. This observation was also supported by Brownlee (2001). 
Previous studies show that moral and epistemological developments are two important aims of teacher education (Ozgelen, 2012; Deniz, 2011; Topcu, 2011). Different educational courses are needed to develop teachers' epistemological beliefs and moral reasoning in teacher education programs. However, in the current teacher education program in Iran, there are no courses which explicitly include epistemological and moral issues. There is a lack of both theoretical courses (including information and explanations of epistemology and morality) and practical courses. Teachers observe their mentors and teach subject knowledge to the students, but they do not consider and discuss any epistemological or moral issues from their student teaching experience in practice teaching courses.

\section{Conclusion}

The findings of the study about the ability to learn, as a component of the English teachers' epistemological beliefs, showed that the teachers generally believed in the two extremes of this scale, suggesting that knowledge both improves with experience and over time and there is an the innate ability to acquire knowledge. This finding is in line with the results of previous studies including Brownlee's (2001) who showed that pre-service teacher students' epistemological beliefs ranged from naive beliefs in the reception of absolute truths to more sophisticated beliefs in the construction of reasoned truths.

Surveying the English teachers' attitudes towards the speed of learning showed that their opinions were distributed almost all across the speed of learning continuum. This was also the case with their views about the stability of knowledge and in general different types of epistemological beliefs. It was also found that there were significant differences among different stages of moral development. Similarly, there were significant differences among the English teachers in terms of the influence of different moral reasoning schemas on them when making judgments about different moral dilemmas. These findings may point to an underlying tradition-versus-modernity conflict in the Iranian education system.

Therefore, authorities in the field of teacher education need to pay more attention to language teachers' epistemological beliefs and raise their awareness in this regard so that teachers can come up with more sophisticated beliefs. Despite all these advantages, however, the relationship between personal epistemology and morality in an educational context cannot always define the ultimate process of decision-making. The results in this study, for instance, revealed a spectrum of (usually conflicting) epistemic and moral possibilities. From a larger perspective, any education system itself rests on its specific epistemology, which may impose institutional conventions on lower strata of the system, thus engendering other possible conflicts in decision-making. A question 
to be addressed in future studies is the way intellectual agents (e.g. teachers) respond to higher levels of institutionally conventionalized knowledge and moral action.

From a global perspective, too, experiences in education can help teachers or decision-makers re-examine their beliefs and epistemological development (Brownlee, 2001). This developmental process, of course, is not limited to agents in any education system, but it should be extended to the learners as well. Regardless of students' epistemology level, instructors should respect learners' assumptions about knowledge and provide appropriate feedback to foster the learning process. The consequences of epistemological beliefs are, however, subtle since many of their effects are mediated by other variables (Cano, 2005). For instance, if learners believe that knowledge is structured as isolated facts, they will be likely to study by memorizing lists of concepts. A change in the belief system, then, can bring about effects in the learning process.

Furthermore, because moral reasoning determines how individuals react to a moral dilemma, educators must specifically focus on the impact of education on moral reasoning. While professional companies, organizations and institutes work based on codes of conduct/ethical guidelines to help their employees resolve moral dilemmas, teachers, on the other hand, have to prepare the initial grounds for learners to be conscious of the overall structure of moral action and to make them aware of the fact that moral judgment is somehow mediated by personal judgment. This understanding could help learners develop a critical approach to moral decisions.

Decision-makers in the field of teacher education can use these findings to improve their teacher development/training programs, helping teachers to develop their epistemological beliefs and moral reasoning up to higher stages. In addition, EFL teachers are encouraged to reflect upon their beliefs about the nature and sources of knowledge, refining such beliefs if necessary. Using the findings of this study can help EFL teachers to develop their epistemological beliefs and moral reasoning, so that they can influence learners' motivation and their learning outcomes more effectively.

\section{References}

Balakrishnan, V., \& Narvaez, D. (2016). A reconceptualisation of Vygotsky's ZPD into ZCD in teaching moral education in secondary schools using real-life dilemmas. Cogent Education, 3(1), 1-15.

Baxter Magolda, M.B. (1993). The convergence of rational and interpersonal knowing in young adults' epistemological development. Paper presented at the Annual Meeting of the American Educational Research Association, Atlanta.

Bendixen, L. D., Schraw, G., \& Dunkle, M. E. (1998). Epistemic beliefs and moral reasoning. The Journal of Psychology, 132(2), 187-200. 
Brownlee, J. (2001). Knowing and learning in teacher education: A theoretical framework of core and peripheral epistemological beliefs. Asia Pacific Journal of Teacher Education \& Development, 4(1), 67-190.

Campbell, E. (2008). The ethics of teaching as a moral profession. Curriculum Inquiry, 38 (4), 357-385.

Campbell, E. (2014). Teaching ethically as a moral condition of professionalism. In Handbook of moral and character education, 2 nd ed., edited by L. Nucci and D. Narváez, 101-118. New York: Routledge.

Cano, F. (2005). Epistemological beliefs and approaches to learning: Their change through secondary school and their influence on academic performance. British Journal of Educational Psychology, 75, 203-221.

Carr, D. (2000). Professionalism and ethics in teaching. London: Routledge.

Chan, K. (2004). Pre-service teachers' epistemological beliefs and conceptions about teaching and learning: Cultural implications for research in teacher education. Australian Journal of Teacher Education, 29. doi:10.14221/ajte.2004v29n1.1.

Chan, K.W. \& Elliot, R.G. (2004). Relational analysis of personal epistemology and conceptions about teaching and learning. Teaching and Teacher Education, 20, 817-831.

Çetin-Dindar, A., Kırbulut, Z. D., \& Boz, Y. (2014). Modelling between epistemological beliefs and constructivist learning environment. European Journal of Teacher Education, 37, 479-496.

Chai, C. S., Khine, M. S., \& Teo, T. (2006). Epistemological beliefs on teaching and learning: A survey among pre-service teachers in Singapore. Educational Media International, 43, 285-298. http://dx.doi.org/10.1080/09523980600926242

Chen, J. A., Morris, D. B., \& Mansour, N. (2015). Science teachers' beliefs: Perceptions of efficacy and the nature of scientific knowledge and knowing. In H. Fives \& M. G.Gill (Eds.), International handbook of research on teachers' beliefs (pp. 370-386). New York, NY: Routledge.

Cheng, M. M. H., Chan, K., Tang, S. Y. F., \& Cheng, A. Y. N. (2009). Pre-service teacher education students' epistemological beliefs and their conceptions of teaching. Teaching and Teacher Education, 25, 319-327.

Deniz, H. (2011). Examination of changes in prospective elementary teachers' epistemological beliefs in science and exploration of factors meditating that change. Journal of Science Education and Technology, 20, 750-760.

http://dx.doi.org/10.1007/s10956-010-9268-x

Dwyer, S. (2009). Moral dumb founding and the linguistic analogy: Methodological implications for the study of moral judgment. Mind \& Language, 24(3), 274-296.

Ferda Bedel, E. (2012). An examination of locus of control, epistemological beliefs 
and metacognitive awareness in preservice early childhood teachers.

Educational Sciences: Theory \& Practice, 3051-3060.

Gibbs, J. C. (2013). Moral development and reality: Beyond the theories of Kohlberg, Hoffman, and Haidt. Oxford University Press.

Gill, M., Ashton, P. \& Algina, J. (2004). Changing preservice teachers' epistemological beliefs about teaching and learning in mathematics: An intervention study. Contemporary Educational Psychology, 29(2), 164-185.

Haidt, J., \& Bjorklund, F. (2008a). Social intuitionists answer six questions about morality. In W. Sinnott-Armstrong (Ed.), Moral psychology: The cognitive science of morality: Intuition and diversity (Vol. 2, pp. 181-218). Cambridge, MA: MIT Press.

Hansen, D. T. (2001). Exploring the moral heart of teaching: Toward a teacher's creed. New York, NY: Teachers College Press.

Hart, D., Matsuba, K., \& Atkins, R. (2014). The moral and civic effects of learning to serve. In L. Nucci, D. Narvaez, \& T. Krettenauer (Eds.), Handbook on moral and character education (2nd ed., pp. 456-470). New York, NY: Routledge.

Horgan, T., \& Timmons, M. (2007). Morphological rationalism and the psychology of moral judgment. Ethical Theory and Moral Practice, 10, 279-295.

Kang, N. (2008). Learning to teach science: Personal epistemologies, teaching goals, and practices of teaching. Teaching and Teacher Education, 24, 478-498. http://dx.doi.org/10.1016/j.tate.2007.01.002

Kohlberg, L. (1971). From is to ought: How to commit the naturalistic fallacy and get away with it in the study of moral development. In T. Mischel (Ed.), Cognitive development and epistemology (pp. 151-284). New York: Academic Press.

Levin, B. (2015). Development of teachers' beliefs. In H. Fives \& M. G. Gill (Eds.), International handbook of research on teachers' beliefs (pp. 48-65). New York, NY: Routledge.

Mansour, N. (2013). Consistencies and inconsistencies between science teachers' beliefs and practices. International Journal of Science Education, 35, 12301275.

Noddings, N. (2002). Educating moral people: A caring alternative to character education. New York, NY: Teachers College Press.

Ozgelen, S. (2012). Exploring the relationships among epistemological beliefs, metacognitive awareness and nature of science. International Journal of Environmental \& science Education, 7, 409-431.

Paxton, J. M., Ungar, L., \& Greene, J. D. (2011). Reflection and reasoning in moral judgment. Cognitive Science, 36 (1), 163-177.

Rabin, C., \& Smith, G. (2013). Teaching care ethics: conceptual understandings and stories for learning. Journal of Moral Education, 42, 164-176. 
Sanger, M. N. (2008). What we need to prepare teachers for the moral nature of their work. Journal of Curriculum Studies, 40 (2), 169-185.

Saunders, L. (2015). What is moral reasoning? Philosophical Psychology, 28 (1), 1-20, DOI: $10.1080 / 09515089.2013 .801007$

Saylan, A., Armağan, F. O., \& Bektaş, O. (2016). The relationship between preservice science teachers' epistemological beliefs and preferences for creating a constructivist learning environment. European Journal of Science and Mathematics Education, 4(2), 251-267.

Schommer, M. (1990). Effects of beliefs about the nature of knowledge on comprehension. Journal of Educational Psychology, 82(3), 498-504.

Schommer, M. (1998). The influence of age and education on epistemological beliefs. British Journal of Educational Psychology 68, 551-562.

Topcu, M. S. (2011). Turkish elementary student teachers' epistemological beliefs and moral reasoning, European Journal of Teacher Education, 34 (1), 99-125.

\section{Contact}

Department of English

Fasa Branch

Islamic Azad University

Iran

aminkarimnia@yahoo.com 